\title{
Sluicing e Pseudosluicing em português europeu e brasileiro*
}

\author{
Gabriela Matos \& Inês Catarino \\ Faculdade de Letras da Universidade de Lisboa, Centro de Linguística da Universidade \\ de Lisboa
}

\begin{abstract}
:
Sluicing and Pseudosluicing are elliptical constructions that differ in Portuguese regarding the (im)possibility of preposition omission. Rodrigues et al. (2009) and Rodrigues (2016) claim that in Brazilian Portuguese (BP), and Spanish, this omission is apparent in Pseudosluicing, because the prepositional phrase occurs inside the elided cleft sentence that affects the overt wh-phrase (whP). European Portuguese (EP) shows that this apparent omission only occurs with whPs that are D-linked and the linguistic context permits the recovering of the nominal that expresses the kind of entities that are under inquire. When free relatives are involved in the cleft sentences, the omission of preposition is required, and the differences in acceptability between PE and PB are due to the narrow extension of the Preposition Drop phenomenon in EP.
\end{abstract}

Keywords: Pseudosluicing, ellipsis, preposition drop, cleft sentences, Portuguese.

Palavras-chave: Pseudosluicing, elipse, Queda de Preposição, frases clivadas, português.

\section{Introdução}

Sluicing (Ross 1969) e Pseudosluicing são construções elípticas em que o remanescente é um sintagma interrogativo (whP) correlato de um constituinte da frase antecedente e o constituinte elidido é de natureza frásica.

(1) O João cumprimentou alguém, mas eu não sei quem [ - ]

(2) O João leu um livro, mas eu não sei qual [ - ]

Distinguem-se porque em Sluicing a frase elidida é um TP recuperado só a partir da frase antecedente, enquanto em Pseudosluicing o TP omitido é precedido por estruturas de clivagem (Merchant 1998, 2001:116).

Nalguns casos, a mesma frase pode ser interpretada como Sluicing ou Pseudosluicing. É o que acontece em (1), que pode corresponder a (3a), uma instância de Sluicing, ou a (3b), uma

\footnotetext{
*A investigação da primeira autora deste trabalho foi desenvolvida no âmbito do projeto UID/LIN/00214/2013, financiado pela Fundação para a Ciência e Tecnologia (FCT). Agradecemos aos dois revisores anónimos de uma versão prévia deste texto as observações que nos fizeram que nos permitiram clarificar vários aspetos deste estudo.
} 
ocorrência de Pseudosluicing. Noutros casos, as frases elíticas são não ambiguamente interpretadas, como acontece em (2), que recebe unicamente a interpretação de Pseudosluicing explicitada em (4a), como mostra a marginalidade da representação de Sluicing, a rasurado em (4b):

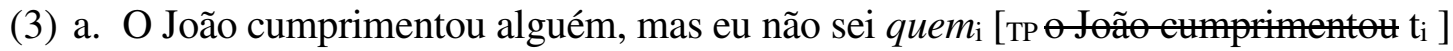

b. O João cumprimentou alguém, mas eu não sei quemi [Clivada foi que [тр $\Theta$ Jөãe eumprimentou $\left.\left.\mathrm{t}_{\mathrm{i}}\right]\right]$

(4) a. O João leu um livro, mas eu não sei quali [Clivada

b. O João leu um livro, mas eu não sei ?? qual [тр $\Theta$ Jøão leu $\mathrm{t}_{\mathrm{i}}$ ]]

Como Almeida e Yoshida (2007) apontaram, em português, Pseudosluicing admite paráfrases em que o verbo copulativo ocorre realizado, propriedade que permite distinguir mais facilmente esta construção de Sluicing:

(5) O João cumprimentou alguém, mas eu não sei quem foi.

(6) O João comprou um livro, mas eu não sei qual foi.

Este estudo debruça-se sobre a variação entre o Português Europeu e Brasileiro (PE, PB) face à omissão de preposição nestas construções. Em Sluicing, ambas as variedades padrão excluem omissão de preposição, como indica o contraste entre (7) e (8) simplificadamente representado em $(8 b)$ :

(7) O João dançou com alguém, mas eu não sei com quem [_ ] (PE, PB)

(8) a. *O João dançou com alguém, mas eu não sei quem. $\quad$ (PE, PB)

b. ..., mas eu não sei quem $\Theta$ Jøão dançeu $t_{i}$

Em Pseudosluicing, estas variedades apresentam um comportamento variável: a omissão de preposição em sintagmas interrogativos (sintagma-wh) discursivamente conectados (D-linked) é aceite tanto em PE como em PB (9); porém, quando tal não acontece, as frases são aceites em PB padrão (Rodrigues et al. 2009), mas consideradas marginais por muitos falantes 
do PE padrão ${ }^{1}$. Note-se, no entanto, que há falantes do PE de uma faixa etária jovem que aceitam exemplos como (10), especialmente no registo coloquial:

a. A Ana dançou com um rapaz mas eu não sei qual.

(PE; PB).

b. A Ana dançou com um rapaz mas eu não sei qual foi.
a. A Ana dançou com alguém, mas eu não sei quem.
(PB: ${ }^{\vee}$, PE padrão:*)
b. A Ana dançou com alguém, mas eu não sei quem foi.

Este facto mostra que em português europeu, há duas gramáticas em confronto, uma mais restritiva do que outra, e que para a gramática mais restritiva não basta a existência de Pseudosluicing para que a omissão de preposição seja legitimada. Neste trabalho procuraremos determinar os motivos que estão subjacentes a esta marginalidade e dar conta do diferente comportamento do PE face ao PB e das duas gramáticas em confronto no PE.

O artigo está estruturado da seguinte forma: na secção 2 recordaremos as propostas que justificam a omissão de preposição em construções de Sluicing e Pseudosluicing em diferentes línguas; na secção 3 consideraremos a questão da marginalidade de omissão de preposição em contextos discursivamente conectados e não-discursivamente conectados em português; na secção 4, procuraremos dar conta dos contrates entre o PE e o PB e da variação no PE nestes últimos contextos; finalmente, na secção 5, apresentaremos uma síntese das posições defendidas.

\section{Sluicing, Pseudosluicing e omissão de preposição}

A possibilidade de omissão de preposição em Sluicing em certas línguas e a sua impossibilidade noutras foi correlacionada por Merchant (2001) com o fenómeno de Abandono de Preposição (Preposition Stranding), e captada pelo autor através da seguinte generalização:

(11) Uma língua L aceita Abandono de Preposição em Sluicing, se e só se L aceitar Abandono de Preposição em movimento-wh.

(Merchant 2001: 92)

\footnotetext{
${ }^{1} \mathrm{O}$ mesmo acontece no espanhol, como reportado em Rodrigues et al. 2009:176:

(i) ??Juan ha hablado com alguien, pero no sé quien.
} 
O inglês é uma língua que permite Abandono de Preposição, por isso, aceita omissão de preposição em Sluicing (veja-se (13b)):

(12) a. Who did John spoke to?

b. The young man $w h o(m)_{1}$ Mary spoke to $\mathrm{t}_{1}$ is nice.

(13) a. John spoke to somebody, but I don't know who

b. $\quad$... but I don't know who $o_{1}$ did he speak to $t_{1}$

O alemão não aceita Abandono de Preposição em movimento-wh, consequentemente, rejeita-o também em Sluicing ${ }^{2}$ :

(14) a. *Wem hat sie mit gesprochen?

quem tem ela com falado

b. Anna hat mit jemandem gesprochen, aber ich weiß nicht, *(mit) wem. Ana tem com alguém falado mas eu sei não com quem (Merchant 2001: 94)

\subsection{O problema levantado pelo português e as hipóteses da literatura}

O português, entre outras línguas, parece invalidar a generalização de Merchant: não tem Abandono de Preposição em construções de movimento-wh interrogativas ou relativas (cf. (15) e (16)), mas exibe omissão de preposição em frases que, à primeira vista, apresentam Sluicing (cf. (17)).

$$
\text { *Quem é que o João dançou com? }
$$

(16) *[O rapaz que a Maria dançou com] é simpático.

(17) A Maria dançou com alguém, mas eu não sei quem.

\footnotetext{
${ }^{2}$ Merchant (2001: 93-100) apresenta dados de várias línguas em suporte desta generalização. Entre as línguas que admitem Abandono de Preposição, encontram-se o Frísio, o Sueco, o Norueguês, o Dinamarquês, o Islandês; entre as línguas que o rejeitam, estão, entre outras, o Grego, o Alemão, o Holandês, o Russo, o Polaco, o Checo, o Catalão, o Espanhol.
} 
Para dar conta deste facto, Almeida e Yoshida (2007) e Rodrigues et al. (2009) apresentam duas propostas antagónicas ${ }^{3}$.

Segundo Almeida e Yoshida 2007), o PB infringe a Generalização de Merchant: não tem Abandono de Preposição em frases não elípticas, mas apresenta-o em Sluicing. Os autores propõem, assim, a seguinte representação para (17):

(18) A Maria dançou com alguém, mas eu não lembro quem 1 a Maria dançou com t $\mathrm{t}_{1}$. (Almeida e Yoshida 2006:350)

Para explicar esta exceção, Almeida e Yoshida sugerem a existência de mecanismos adicionais subjacentes à gramática das línguas que, embora sem Abandono de Preposição explícito, admitem a omissão de preposição em Sluicing. Nestas línguas haveria Abandono de Preposição na Sintaxe, mas este seria bloqueado em Forma Fonética por uma condição fonológica (Aoun et al. 1987) ou, alternativamente, por uma condição de Forma Lógica que estipularia que a identidade de traços dos núcleos das fases (phases) é irrelevante para a elipse e pode ser captada por mudança de veículo (ing. vehicle change), como sugerido em Abels (2013).

Por sua vez, Rodrigues et al. (2009) consideram que o PB manifesta omissão de preposição em Pseudosluicing, e não em Sluicing, pelo que não infringe a generalização de Merchant. Desenvolvendo a análise de Merchant (2001) de Pseudosluicing, Rodrigues et al. (2009) apresentam para o PB estruturas de clivagem em que o sintagma preposicional relativizado é movido e anteposto à frase relativa incluída na estrutura de clivagem, como ilustrado em (19b):

(19) a. O João falou com um amigo mas eu não sei quem.

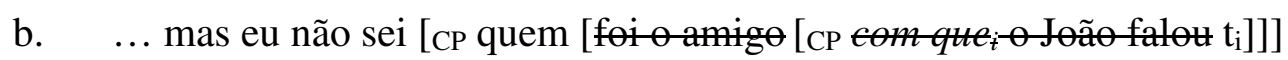

\footnotetext{
${ }^{3}$ Rodrigues et al. (2009) analisam igualmente os casos de omissão de preposição do espanhol em Pseudosluicing encabeçado por whP D-Linked:

(i) Juan ha hablado con una chica, pero no sé qual. (Rodrigues et al. 2009: 176).
} 
Assim, a omissão de preposição em Pseudosluicing é aparente, uma vez que o sintagma preposicionado ocorre no interior da frase clivada encabeçando a relativa que afeta o constituinte nominal, em (19) o amigo.

\subsection{Argumentos para (Pseudo)Sluicing em contexto de omissão de preposição}

Almeida e Yoshida (2007) e Rodrigues et al. (2009), retomam os testes de Merchant para o inglês (2001: 129-127), para provar que em PB: (i) existe Sluicing com Abandono de Preposição (Almeida e Yoshida 2007); (ii) ou, pelo contrário, Pseudosluicing com aparente omissão de preposição (Rodrigues et al. 2009). Neste artigo passaremos em revista os argumentos e contra-argumentos apresentados para o PB que nos parecem mais evidentes, confrontando as suas predições com os dados do PE.

\subsection{1. whPs não discursivamente conectados}

Merchant (2001), considera que os whPs que são não discursivamente ligados (ing. agressivly non D-linked) estão excluídos de Sluicing, mas podem ser o pivot de clivadas.

Almeida eYoshida (2007: 354) acreditam que esta propriedade mostra que o PB tem Abandono de Preposição em Sluicing, dado que estes itens podem constituir expressões de foco em estruturas clivadas (20), mas são ilegítimos em frases que exibem aparentemente Sluicing, (21).

(20) Que raio é que a Maria viu?

(21) A Maria dançou com um outro cara ontem à noite:

a. Eu só queria saber (com) quem!

b. Eu só queria saber *(com) quem diabos foi!

c. Eu só queria saber *(com) quem diabos!

(Almeida e Yoshida (2007: 354)

Rodrigues et al. (2009) rejeitam este argumento, salientando que em PB, estas frases são excluídas mesmo sem omissão da preposição. Assim, o exemplo correspondente a (21c) sem omissão de preposição é malformado:

(22) A Maria dançou com um outro cara ontem à noite.

*Eu só queria saber com quem diabos! (cf. 21c) 
Este facto invalida a relevância do argumento de Almeida e Yoshida (2007) de que Sluicing está presente nos casos de omissão de preposição no PB.

Note-se que o PE parece ter um comportamento próximo do PB, embora a ausência de preposição acentue a marginalidade das frases ${ }^{4}$ :

(23) A Maria falou com alguém no restaurante.

$(\mathrm{PE})$
a. *Só gostava de me lembrar quem diabo!
b. ??Só gostava de me lembrar com quem diabo!
c. *Só gostava de me lembrar que diabo!
d. ??Só gostava de me lembrar com que diabo!

(24) Sujei-me ontem com qualquer coisa,
a. *mas não consigo perceber que raio!
b. ??mas não consigo perceber com que raio!

Rodrigues et al. (2009) mostram ainda que as frases com Preposição+whPs agressivamente não discursivamente conectados (agressively non-D-linked) melhoram quando o verbo copulativo é realizado.

A Maria dançou com um outro cara ontem à noite. Eu só queria saber com quem diabos foi!

O mesmo acontece em PE:

(26) a. Sujei-me ontem com qualquer coisa, mas não consigo perceber com que raio foi!

b. O Pedro pediu-me uma opinião sobre algo ontem. Gostava de me lembrar sobre que diabo foi!

\footnotetext{
${ }^{4}$ A expressão quem diabos, presente em Rodrigues et al. (2009), parece não ter correspondente em PE. Assim, no CRPC (Corpus de Referência do Português Contemporâneo), quem diabos não apresenta qualquer ocorrência, quem diabo ocorre 15 vezes, que diabos aparece apenas 8 vezes, mas que diabo é atestado com 325 ocorrências.
} 
Rodrigues et al. (2009) atribuem a obrigatoriedade de realização da cópula a questões fonológicas: o acento de foco não deve recair apenas sobre os whPs agressivamente nãodiscursivamente conectados.

\subsubsection{Modificação com "mais"}

Merchant (2001) mostra que em inglês else pode ocorrer em Sluicing mas não em Pseudosluicing, porque em inglês o pivot das clivadas impõe uma interpretação de "menção a todos":

$$
\begin{aligned}
& \text { Harry was there, but I don't know who else. } \\
& \text { a. ... but I don't know who *(else) it was that was there. } \\
& \text { b. ... but I don't know who else was there. }
\end{aligned}
$$

Almeida e Yoshida (2007), considerando a aceitabilidade de frases como a seguinte, assumem que no PB há Sluicing com Abandono de Preposição, como representado em (28b):

$$
\begin{aligned}
& \text { a. O João saiu com a Maria, mas não sei quem mais. } \\
& \text { b. ... mas não sei quem mais @ Jøão saiu com. }
\end{aligned}
$$

Mantendo a análise de Pseudosluicing, Rodrigues et al. (2009) mostram que as interrogativas clivadas aceitam a presença do advérbio mais em PB.

(29) Me fala quem mais é que você vai convidar para a festa.

Consequentemente, Rodrigues et al. (2009) admitem a ocorrência de mais em Pseudosluicing nos casos de omissão de preposição em PB.

Em PE, mais ocorre igualmente em interrogativas clivadas 5 :

\footnotetext{
${ }^{5}$ Nos exemplos em (30), (31) e (32) usam-se as clivadas canónicas com a estrutura Ser_Fexionado ... que e não a expressão invariável é_que. Com efeito, como veremos adiante neste trabalho (secção 3.1), nas interrogativas em PE, é_que tem um comportamento específico.
} 
Porém, em PE, a ocorrência de mais em Pseudosluicing com omissão de preposição é marginal, como mostra o contraste entre exemplos em que o whP da relativa está associado à posição de sujeito e aqueles em que está associado a um PP:

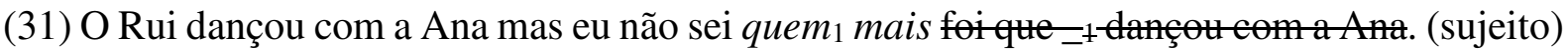
(32) *O Rui dançou com a Ana mas eu não sei quem 1 mais føi com que f $_{-} \odot$ Rui danç@u $t_{1}$. (PP)

Com efeito, na última frase a interpretação de quem como integrado num complemento oblíquo não é recuperável e a presença explícita da preposição no sluice é requerida:

(33) O Rui dançou com a Ana mas eu não sei com quem mais.

\subsubsection{Recuperação de sintagma em perguntas fragmentárias}

Rodrigues et al. (2009), baseando-se no trabalho de Arregui (2007) para o espanhol, mostram que o PB admite, na sequência de interrogativas-wh, perguntas elípticas, em que a omissão de preposição só é legítima quando na frase antecedente ocorre uma clivada (vejam-se os exemplos (34a) e (35a) de Rodrigues et al. (2009:190). O mesmo acontece em PE, como ilustrado em (34b) e (35):

a. Com qual menina ele saiu, *(com) a Elena?

b. Com que aluno falou o professor, *(com) o Afonso?

a. Qual é a menina com quem ele saiu, (*com) a Elena?

$(\mathrm{PB} / \mathrm{PE})$

b. Quem é o aluno com quem o professor falou, (*com) o Afonso? (PB/PE)

Nos casos acima, a estrutura da frase elítica é recuperada a partir da antecedente. Considerando os exemplos do PE (correspondentes aos do PB), em (34b) é recuperada a frase não clivada [ $\theta$ prefessor falou *(com) que aluno] e a omissão da preposição provoca marginalidade; pelo contrário, (35b) é interpretado como uma construção clivada, [O Afonso é o aluno com quem o professor falou]; por isso, a presença da preposição na pergunta 
fragmentária produziria agramaticalidade (cf. *Com o Afonso falou).

Em suma, em Pseudosluicing, a clivagem pode legitimar omissão de preposição em PE e em PB. Não é necessário admitir que o português (PE, PB) exibe Abandono de Preposição ou que infringe a generalização de Merchant. Porém, nos casos com whPs não-discursivamente conectados e com o adverbial modificador mais, o PB e o PE diferem, sendo a omissão de preposição marginal em PE padrão.

\section{Pseudosluicing e omissão de preposição em português}

Partindo de Rodrigues et al. (2009), consideremos a estrutura a atribuir a Pseudosluicing com omissão de preposição em português, tanto nos casos em que os sintagmas-wh realizados são discursivamente conectados (D-linked) como naqueles em que tal não acontece.

\subsection{Pseudosluicing com sintagmas-wh discursivamente conectados}

Quando o whP realizado é discursivamente conectado, o sintagma-wh preposicionado é movido para o início da frase relativa que modifica um DP elidido, sendo o conteúdo referencial do núcleo nominal recuperado a partir da frase antecedente (cf., em (36), amigo):

(36) A Maria falou com um amigo, mas eu não sei qual [føi $\bullet$ amige [eøm que a a Maria falou $\left.\left.\mathbf{t}_{\mathbf{i}}\right]\right]$

Quanto à estrutura da frase clivada em Pseudosluicing, Rodrigues et al. (2009: 177) caracterizam-na como uma copulativa especificacional, cuja parte elidida é um TP:

(37) A Maria falou com um amigo, mas eu não sei [сР qual [тр føi ... ]] 
A caracterização das frases clivadas canónicas e das Pseudoclivadas como estruturas copulares é consensual na literatura atual (cf. Costa e Duarte 2001; Lobo 2006 e Costa e Lobo 2009, para o PE, e Mioto e Lobo 2016, para um confronto entre o PB e o PE) ${ }^{6}$. Porém a clivada de "é que" em PE é analisada como uma expressão fixa que ocupa a posição de complementador (vejam-se os trabalhos previamente referidos) ${ }^{7}$.

Segundo Rodrigues et al. (2009), em Pseudosluicing com Omissão de Preposição, o whP realizado é o pivot da frase clivada, e move-se da posição de sujeito do verbo copulativo ${ }^{8}$. Assumindo esta análise, obteríamos a seguinte representação simplificada, em que o complemento oracional do verbo ser não é integralmente especificado:

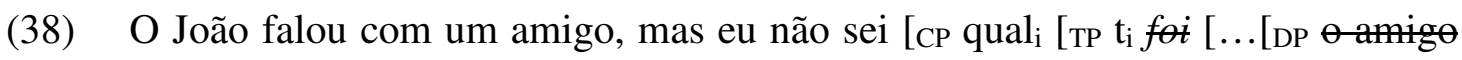
eom que - - Jøão falou $\mathrm{t}_{\mathrm{j}}$ ] ...] ] ]

No PE, três propriedades distintas convergem para mostrar que o whP explicitamente realizado ocorre como o sujeito da clivada. Em primeiro lugar, como Mioto e Lobo (2016) salientam, as interrogativas-wh clivadas permitem que o sujeito subsequente ao elemento que ocupe uma posição pré-verbal, como ilustrado em (39), em que Joana precede o verbo fazer.
a. $\quad$ O que foi que Joana fez? (Mioto e Lobo 2016: 277)
b. O que é que Joana fez?

\footnotetext{
6 Os estudos sobre as clivadas têm tipicamente considerado frases declarativas, como, por exemplo, as seguidamente ilustradas:

(i) Foi o amigo que a Ana viu.

(ii) Quem viu a Ana foi o amigo.

(iii) Foi o amigo quem viu a Ana., para o PE e o PB, debruçam-se sobre interrogativas clivadas.

${ }^{7}$ Mioto e Lobo referem ainda que é que em PE está mais gramaticalizado do que em PB. Em PB é que confere à questão um valor enfático (Mioto e Lobo 2016: 278, 279), que parece ser ténue nas interrogativas em PE, e não se comporta como uma expressão fixa, nomeadamente no que diz respeito à forma do verbo ser, que em PB flexiona em tempo. É, pois, possível que é que em PB apresente uma estrutura diversa da presente na variedade europeia. Sobre é que veja-se ainda a nota 8

${ }^{8}$ Cf. Merchant (2001:116), para casos de Pseudosluicing sem Omissão de Preposição e sem whP D-linked no inglês, em que o constituinte-wh é movido a partir da posição de complemento da oração copulativa, deixando in situ a frase de tipo relativo que o modifica:

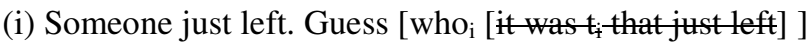


Em segundo lugar, a gramaticalização de é que em PE permite que nas interrogativaswh esta expressão fixa coocorra com a clivada canónica (Serflexionado ... que). Os exemplos em (40) mostram que tal acontece tanto em interrogativas diretas como em interrogativas indiretas (subordinadas) $)^{9}$ :

(40) a. (O) que é que foi que o João comprou?

b. O Pedro não sabe [(o) que é que foi que o João comprou_]

Por fim, note-se que em interrogativas-wh discursivamente conectadas em que é que coocorre com a clivada canónica, é impossível colocar o DP modificado pela relativa (em (41b), o livro que o João comprou) na posição de sujeito da frase copulativa, como seria de esperar se este DP funcionasse como sujeito de foi (recorde-se que, como vimos em (39b), é que legitima sujeito pré-verbal):

(41) a. Qual é que foi o livro que o João comprou?

b. *Qual é que o livro que o João comprou foi?

Tal corrobora as propostas de que em frases interrogativas em PE é que é diretamente inserido em complementador, sendo equivalente a que em $\mathrm{PB}$, e que o pivot da clivada canónica é o sujeito. A representação (42) visualiza esta análise:

(42) [cР qual ${ }_{i}\left[\mathrm{c}\right.$ é que] [тP $\mathrm{t}_{\mathrm{i}}$ foi [o livro que $\mathrm{k}$ o João comprou $\left.\left.\left.\mathrm{t}_{\mathrm{k}}\right]\right]\right]$ ?

\footnotetext{
${ }^{9}$ Note-se que essa gramaticalização parece estr num estádio mais avançado nas frases interrogativas. Assim, em PE é que tem um comportamento distinto nas clivadas declarativas e nas interrogativas. Nas declarativas é que não pode coocorrer com frases clivadas canónicas (cf. (ia), por oposição a (ib) e (ic)). O mesmo não acontece nas interrogativas, como mostram os exemplos em (40) e em (ii)):

(i) a. ?? O Rui é que foi que dançou com a Ana. (frase declarativa com é_que + clivada canónica)

b. Foi o Rui que dançou com a Ana (frase declarativa com clivada canónica)

c. O Rui é que dançou com a Ana (frase declarativa com clivada de é_que)

(ii) Quem é que foi que dançou com a Ana? (frase interrogativa com é_que + clivada canónica) Este contraste parece indicar que a expressão é que nas interrogativas não assume o valor característico das construções de clivagem.
} 
Esta mesma análise é extensível aos casos de omissão de preposição em Pseudosluicing com whP discursivamente conectado:

(43) A Ana falou com um amigo, mas eu não sei [ср qual [тр $_{\text {i }}$ fei-[ $\theta$ amige [eøm que a Ana falou $_{\mathrm{j}}$ ] ] ]

\subsection{Pseudosluicing com sintagmas-wh não-discursivamente conectados}

Adotando a análise de omissão aparente de preposição advogada por Rodrigues et al. (2009) e Rodrigues (2016), seria de supor que tanto o PB como o PE aceitassem como bem formadas frases com whP não discursivamente conectado. Porém, embora sejam consideradas bem-formadas no PB padrão (cf. (10) acima), estas frases não são aceites por muitos falantes do PE padrão, como mostra o contraste entre os casos (a) e (b) dos exemplos seguintes, em que ocorrem complementos oblíquos de verbos que exibem diferentes preposições, dançar com, participar em, obedecer a, falar de $e^{10}$.

(44) a. *A Ana dançou com alguém, mas eu não sei quem.

(PE padrão)

b. A Ana dançou com alguém, mas eu não sei com quem.

(45) a. *A Ana participou em algo, mas eu não sei o quê.

(PE padrão)

b. A Ana participou em algo, mas eu não sei no quê.

(46) a. *A criança obedeceu a alguma pessoa, mas resta saber quem. (PE padrão)

b. A criança obedeceu a alguma pessoa, mas resta saber a quem.

(47) a. ??A Ana falou de um amigo, mas eu ignoro quem.

(PE padrão)

b. A Ana falou de um amigo, mas eu ignoro de quem.

É importante sublinhar que os juízos que recolhemos junto de falantes nativos do português europeu sugerem que no PE há atualmente duas gramáticas em vigor: uma gramática mais conservadora, tipicamente falada por falantes mais velhos e associada àquela que é considerada a norma padrão do PE, que considera os exemplos das alíneas (a) de (44)-(47) agramaticais ou marginais; e uma outra gramática, falada por sujeitos mais novos, que admite

\footnotetext{
${ }^{10}$ Note-se que, nestes exemplos há diferenças de aceitabilidade correlacionadas com o verbo e a preposição por ele selecionada. Assim (47a) é mais aceitável do que (44a), (45a) e (46a).
} 
a boa-formação dos referidos exemplos, sobretudo em registos coloquiais ${ }^{11}$. É a gramática mais conservadora que designamos por PE padrão, e que procuraremos caracterizar seguidamente.

As paráfrases não elípticas de (44a) e (45a) sugerem que a sua marginalidade decorre da impossibilidade de recuperação adequada do conteúdo do constituinte nominal modificado pela relativa:

(48) a. *A Ana dançou com alguém, mas eu não sei quem foi (o) alguém com que(m) a Ana dançou.

b. *A Ana participou em algo, mas eu não sei o que foi (o) algo em que a Ana participou.

Porém, as correspondentes não-elípticas de (46a) e (47a) são ambas bem formadas, como ilustrado em (49). Se (46a) e (47a) tivessem estruturas subjacentes idênticas a (49), deveriam ter um estatuto de aceitabilidade semelhante, diferentemente do que acontece:

(49) a. A criança obedeceu a alguma pessoa, mas resta saber quem foi a pessoa a que $(\mathrm{m})$ a criança obedeceu.

b. A Ana falou de um amigo, mas eu ignoro quem foi o amigo de que(m) a Ana falou.

Estes dados mostram que nas clivadas com relativas encabeçadas por quem ou o quê, a recuperação do conteúdo do antecedente do relativo não é feita por um elemento presente no discurso prévio. Este facto é compatível com a hipótese de Rodrigues et al. 2009 de que Pseudosluicing com interrogativas-wh não discursivamente conectadas mobiliza relativas livres, ou seja usa uma estratégia de Pseudoclivagem (vejam-se, para o PE e o PB, os exemplos de Pseudoclivadas referidos em Mioto e Lobo 2016).

As relativas livres são frequentemente analisadas como contendo um antecedente omitido, o pronome nulo pro (Brito 1991, 2003; Móia 1996). De acordo com esta análise, as contrapartidas não elípticas de (44a), (45a) e (46a) são as presentes em (50a), (51a) e (52a), que

\footnotetext{
${ }^{11}$ Em trabalho futuro, seria interessante investigar a ocorrência deste tipo de estruturas em corpora orais e escritos do PE.
} 
mantêm a marginalidade dos exemplos elípticos. As suas representações simplificadas são apresentadas em (50b), (51b) e (52c):

(50) a. *A Ana dançou com alguém, mas eu não sei quem foi com quem a Ana dançou.

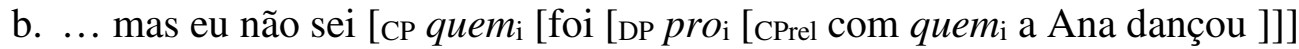

(51) a. *A Ana participou em algo, mas eu não sei o que foi no que a Ana participou.

b. ... mas eu não sei [ср $o q u e_{\mathrm{i}}$ [foi [DP $p r o_{\mathrm{i}}$ [CPrel no que $e_{\mathrm{i}}$ a Ana participou ]]]

(52) a. *A criança obedeceu a alguma pessoa, mas resta saber quem foi a quem a criança obedeceu.

b. ...mas resta saber [quem ${ }_{\mathrm{i}}$ [foi [DP pro $_{\mathrm{i}}$ [CPrel a quem $\mathrm{i}$ a criança obedeceu ]]]

Admitimos que o conteúdo referencial de pro é localmente determinado pelos traços do sintagma-wh interrogativo pivot da clivada. Assim, pro é caracterizado como um núcleo nominal que apresenta os traços [+humano, +específico] quando ocorre quem, e [-humano, +específico], quando surge o que. Entre o sintagma-wh interrogativo, pro e o sintagma-wh da relativa estabelece-se uma relação de partilha de traços, visualizada na coindexação presente nas representações (50b), (51b) e (52b), acima.

A questão seguinte reside em explicar a marginalidade destas frases em PE padrão:
a. *A Ana dançou com alguém, mas eu não sei quem.
b. ... mas eu não sei [CP quem [foi [DP pre [CPrel eøm quem a Ana dançeu t]]]

Consideramos que a marginalidade de omissão de preposição em contextos de Pseudosluicing com whP não-discursivamente conectados decorre de dois fatores correlacionados. Por um lado, deve-se ao facto de pro ter um conteúdo nominal fraco que o torna incapaz de estabelecer um referente discursivo para o relativo. O contraste de aceitabilidade entre as frases não elípticas com relativa livre (cf. (50a), repetida em (54a)) versus com relativa com antecedente realizado (cf. (54b)) atesta esta propriedade: 
(54) a. *A Ana dançou com alguém, mas eu não sei quem foi pro com quem a Ana dançou.

b. A Ana dançou com alguém, mas eu não sei quem foi a pessoa com quem a Ana dançou.

Por outro lado, em consequência da natureza referencialmente pobre de pro, a inaceitabilidade dos exemplos (53a) e (54a) deve-se ao facto de na estrutura pseudoclivada, a oração copulativa estabelecer uma relação especificacional inadequada entre o DP interrogativo realizado e o PP relativo elidido. Com efeito, em (44a), retomado em (53), quem funciona como uma expressão a que não é atribuído o valor de uma entidade, pela presença de uma expressão nominal, mas sim o valor de um fragmento do predicado dançar(com), ou seja, com quem (cf. $(55))$ :

(55) ... quem foi ... com quem a Ana dançeu $\mathrm{t}$

A marginalidade de exemplos com omissão de preposição, como (53a), e a aceitabilidade de frases com constituintes de natureza nominal, como (56a), corroboram esta análise ${ }^{12}$ :

(56) a. A Ana cumprimentou alguém mas eu não sei quem.

b. ... mas eu não sei [CP quem [foi [DP pre [CP rel quem a Ana cumprimentou t]]]]

Assim, a boa formação de (56) deve-se à conformidade categorial entre os constituintes relacionados, que são ambos identificados como constituintes nominais (cf. (57)):

(57) ... quem foi ... quem a Ana cumprimentou $\mathrm{t}$

\footnotetext{
${ }^{12}$ Recorde-se que, como frisámos previamente ao confrontarmos (46a) com (49a), a representação (i), alternativa a (56b), que contém dentro do material elidido o DP a pessoa, não parece viável, pois se o fosse, na gramática padrão, o exemplo (53a), repetido em (ii), deveria ser bem formado, como é a sua contrapartida não elítica, em (iii):

(i)... mas eu não sei [CP quem [føi [DP a pessea $\mathrm{a}_{\mathrm{i}}$ [CP rel que a Ana cumprimentou $\left.\mathrm{t}_{\mathrm{i}}\right]$ ]]]

(ii) *A Ana dançou com alguém, mas eu não sei quem.

(iii) A Ana dançou mas eu não sei quem foi a pessoa com quem a Ana dançou.
} 
Em suma, em Pseudosluicing com sintagmas-wh não-discursivamente conectados, a estratégia de clivagem usada é a Pseudoclivagem, que recorre a relativas livres. Dada a estrutura do constituinte nominal que contem a relativa e a natureza especificacional das frases copulativas envolvidas, a conformidade categorial entre os constituintes-wh relacionados é requerida.

\section{As diferenças de aceitabilidade entre o PE e o PB}

Os dados analisados na secção anterior mostram que nem todos os casos de omissão de preposição em português europeu padrão podem ser legitimados por Pseudosluicing ${ }^{13}$. Exemplos como (58) sugerem que a legitimidade de omissão de preposição em Pseudosluicing com sintagmas-wh não discursivamente conectados em PB (e na gramática não-padrão do PE) corresponde a uma queda real da preposição:

(58) O João dançou com alguém, mas eu não sei quem. ${ }^{14}$ (PB: $\sqrt{ }, \mathrm{PE}$ padrão:*)

Efetivamente, Rodrigues et al. (2009:191) consideram que (58) apresenta correlatos não elíticos bem-formados como (59), em que a queda de proposição ocorreu, que são excluídos no PE padrão, e propõem para (58) em PB a representação explicitada em (60) (Rodrigues et al 2009: 192):

(59) O João dançou com alguém mas eu não sei quem é que o João dançou. (PB: $\sqrt{\text {, }}$ PE padrão:*)

(60) O João dançou com alguém mas eu não sei [cP quem [ipé [que o Jeão dançøu]]] (cf. (58))

\footnotetext{
${ }^{13} \mathrm{O}$ mesmo sucede em espanhol.

${ }^{14}$ Mesmo para vários falantes do PE padrão, há uma diferença de aceitabilidade entre os exemplos como (58), repetido em (i), e exemplos como (ii). Agradecemos a um dos revisores o ter-nos chamado a atenção para esta questão.

(i) *O João dançou com alguém, mas eu não sei quem. (PE padrão)

(ii) ? O João dançou com alguém, mas eu não sei quem. (PE padrão)

Note-se que (i) é uma instância de Pseudosluicing (i.e. elipse do TP) não discursivamente conectado, enquanto (ii) é um caso de elipse do complemento do verbo de cópula da clivada. Esta última construção e o seu confronto com Pseudosluicing merecem um estudo sistemático, que está fora do âmbito do presente artigo.
} 
Este facto aponta, pois, para uma explicação do contraste de aceitabilidade deste tipo de exemplos em PB e PE padrão em termos de Queda de Preposição. Com efeito, a variação de aceitabilidade entre as seguintes frases no PE mostra que Pseudosluicing não discursivamente conectado é sensível ao verbo que seleciona o PP (cf. em (61), refletir sobre, dançar com, gostar de) e à preposição que ocorre no PP (cf. em (61), falar de, falar sobre, falar com):

(61) a. *O Pedro refletiu sobre algo, mas eu não sei o quê.

b. $\quad$ * O Pedro dançou com alguém, mas não me lembro quem.

c. (?) A Ana gostava de alguém, mas eu não sei quem.

d. ?O João falou de algo, mas eu não sei o quê.

e. ??O João falou sobre algo, mas eu não sei o quê.

f. ??O João falou com alguém, mas eu não sei quem.

Como é sabido, a Queda de Preposição é lexicalmente regulada e ocorre nas diferentes línguas com alguns verbos e algumas preposições, e está sujeita a variação idioletal. No português europeu, verbos como gostar de ou falar de são dos que mais facilmente permitem a Queda de Preposição. Pelo contrário refletir sobre e dançar com não admitem tão facilmente essa queda:

(62) a. ?Este foi o assunto que o Pedro falou. (PE padrão)

b. *Esta foi a pessoa que o Pedro dançou.

(PE padrão)

Esta análise é corroborada pela variação de aceitabilidade de frases com Queda de Preposição em português europeu não padrão, especialmente em casos de ocorrência de relativas, como os atestados em Peres e Móia (1995) e Alexandre (2000), entre outros.

Deste modo, a representação a atribuir a exemplos como (61c), seria a explicitada em (63), onde se verifica efetivamente a Queda de Preposição do sintagma-wh da relativa:

(63) a. A Ana gostava de alguém, mas eu não sei quem.

b. ... mas eu não sei [cr quem ${ }_{i}$ era [DP pre [CP quem ${ }_{i}$ a Ana gostava $\left.\left.t_{i}\right]\right]$ ] 
A Queda de Preposição permite que os constituintes relacionados em Pseudosluicing partilhem conformidade categorial, são ambos constituintes de natureza nominal, e explica a marginalidade em PE padrão das frases resultantes, na medida em que a Queda de Preposição infringe a seleção categorial dos verbos envolvidos

Assim, atribuímos a diferença de comportamento entre o PE e o PB nestes contextos, à maior facilidade do PB em usar a estratégia de Queda de Preposição. A mesma explicação pode aplicar-se à gramática menos restritiva do PE, que designámos como não-padrão.

\section{Sintetizando}

Sluicing e Pseudosluicing diferem pela impossibilidade versus possibilidade de omissão de preposição. No entanto, o PB e o PE padrão (a gramática mais conservadora) diferem quanto à extensão de omissão de preposição em Pseudosluicing: esta omissão é possível na generalidade dos casos em PB, mas inaceitável no PE em contextos em que o remanescente da frase elítica se reduz a um sintagma interrogativo não discursivamente conectado (non $D$ linked).

Como mostram Rodrigues et al. (2009), a omissão de preposição em Pseudosluicing é aparente quando ocorrem sintagmas-wh discursivamente conectados (D-linked). Tal verificase tanto ao PB como ao PE. Porém, esta análise não é extensível aos casos em que o sintagma interrogativo não é discursivamente conectado e não ocorre explicitamente o verbo de cópula da frase clivada, uma vez que, se assim fosse, se prediria que em PE as frases obtidas eram bem formadas, contrariamente aos factos. Admitimos que nestes casos em que o remanescente da elipse é apenas um sintagma-wh não discursivamente conectado, a omissão de preposição se deve a Queda de Preposição, um fenómeno lexicalmente regido e sujeito a variação entre os falantes de uma mesma língua. Assim, assumimos que a diferença de comportamento do PE e do PB face à omissão de preposição nestes contextos de Pseudosluicing decorre da maior facilidade de Queda de Preposição no PB, facto independentemente atestado na literatura. 


\section{Referências}

Abels, Kaus (2003) Successive cyclicity, anti-locality and adposition stranding. PhD Dissertation. University of Connecticut, Storrs.

Alexandre, Nélia (2000) A estratégia resumptiva em relativas restritivas do português europeu. Dissertação de Mestrado, Faculdade de Letras da Universidade de Lisboa.

Almeida, Diogo e Masaya Yoshida (2007) A problem for the Preposition Stranding Generalization. Linguistic Inquiry. 38: 349-362.

Aoun, Joseph, Norbert Hornstein, David Lightfoot, and Amy Weinberg (1987) Two types of locality. Linguistic Inquiry 18:537-577.

Arregui, Karlos (2007) Ellipsis in split questions. http//ling.auf.net/lingBuzz/000542 .

Brito, Ana Maria (2003) Frases interrogativas. In Mateus, Mª H., A. Mª Brito, I Duarte, I. Faria, S. Frota, G. Matos, F. Oliveira, M. Vigário e A. Villalva (2003) Gramática da língua Portuguesa. Lisboa: Editorial Caminho, p. 472.

Costa, João e Inês Duarte (2001) Minimizando a estrutura: uma análise unificada das construções de clivagem em português. In Correia, C e A. Gonçalves (eds.) Actas do do XVI ENAPL. Lisboa: APL/ Colibri, pp. 627-638.

Costa, João e Maria Lobo (2009) Estruturas clivadas: evidência dos dados do português europeu não-standard. Anais do Congresso internacional da Abralin, João Pessoa, 2009, vol 2. João Pessoa: Universidade Federal do Paraná, pp. 3800-3806

Merchant, Jason (1998) Pseudosluicing: Elliptical clefts in Japanese and English. In Alexiadou, A., N. Fuhrhop, P. Law e U. Kleinhenz (eds.) ZAS Working Papers in Linguistics, 10, Berlin: Zentrum fur Allgemeine Sprachwissenschaft, pp. 88-112.

Merchant, Jason (2001) The syntax of silence: Sluicing, islands, and the theory of ellipsis. Oxford: Oxford University Press.

Mioto, Carlos e Maria Lobo (2016) Wh-movement interrogatives, relatives and clefts. In Wetzels, W. Leo, Sérgio Menuzzi e João Costa (eds.) The Handbook of Portuguese Linguistics. Wiley-Blackwell, pp. 275-293.

Móia, Telmo (1996) A Sintaxe das orações relativas sem antecedente expresso do Português. Quatro Estudos em Sintaxe do Português. Uma Abordagem segundo a Teoria dos Princípios e Parâmetros, Lisboa: Edições Colibri, pp. 149-188.

Peres, João e Telmo Móia (1995) Áreas críticas da língua portuguesa. Lisboa: Editorial Caminho. 
Rodrigues, Cilene, Andrew Nevins e Luis Vicente (2009) Cleaving the interactions between Sluicing and Preposition Stranding. In Torck, Danièle and W. Leo Wetzels. Romance Language and Linguistic Theory. Amsterdam: John Benjamins, pp. 175-198.

Rodrigues, Cilene (2016) Guess what? Clefts are what are silent here. Linguíftica, vol.12, número 2, pp. 23-32.

Ross, John R. (1969) Guess who? In Binnick, R. (ed.) Proceedings of the Fifth Regional Meeting of the Chicago Linguistic Society. Chicago: University of Chicago, Chicago Linguistic Society, pp.252-286.

CRPC-Corpus de Referência do Português Contemporâneo ISRN-982-545-991-0 http://alfclul.clul.ul.pt/CQPweb/ 